\title{
Study on Landscape Plant Construction of Small Courtyard in Areas South of the Yangtze River
}

\author{
Yifan Zhang \\ Jingdezhen Ceramic University, Jingdezhen, Jiangxi 333403
}

\begin{abstract}
With the development of the society and the intensification of modernization process, cities and towns are gradually surrounded by steel and concreate, and people are eager to find a green land in the cement jungle and enjoy the accompany of plants. Because of the unique geographical location, climate characteristics and cultural history different from that in other regions, small courtyard plant landscape design in regions south of the Yangtze River are different to some extent from the plant and landscape design in landscaping we are familiar with. This paper analyzes and studies the spatial creation methods and design key points of small courtyard landscape and plants.
\end{abstract}

Keywords: Regions south of the Yangtze River, Small courtyard, Landscape and plant space

\section{江南地区小庭院景观植物空间营造研究}

\author{
张一帆 \\ ( 景德镇陶瓷大学 江西 景德镇 333403 )
}

摘要: 随着社会的的发展和现代化进程的加剧, 城镇已经渐渐被钢筋和混泥土所包围, 人们渴望在水泥丛林里找到一 片绿色的天地, 能在居住环境附近享受植物的陪伴。江南地区因其独特的地理位置、气候特点和人文历史有着不同与其他地 区的特点, 江南地区小庭院植物景观设计我们所熟知的园林绿化中的植物景观设计也有着一定的差异, 本文就小庭院景观植 物的空间营造方法和设计要点进行分析研究。

关键词: 江南地区、小庭院、景观植物空间

中图分类号: J021 文摘标识码: A

引言

从先秦时期开始, 中国人就从未停止过 “造园” , 最早对于园林的理想来自于 “蓬莱”。人们一直在 寻找自己心中的 “桃花源”。庭院是一种历史悠久、应用广泛、形态多样的建筑空间类型, 《中-国大百 科全书 (园林卷) 》中对 “庭院” 的解释为: “建筑物前后左右或被建筑物包围的场地通称为庭或庭院”。 我们可以将庭院的概念进一步解释为：庭院是由建筑和实体 (墙、植物等) 围合的、内向型的、有明确边 界的、对外封闭的空间，庭院是一种广泛使用的建筑外部空间形式，是自然空间和建筑空间的互相渗透。 不论国内外庭院, 都希望创造一种人与自然和谐共处的理想化景观, 是人们热爱自然、亲近自然的表现。

\section{1. 小庭院景观现状}

小尺度庭院其实是城市化进程的结果，在中国三线城市，尤其是在江南地区根据地形特点，低楼层的 住宅和各类私建房屋星密布在各个城区。由此而来的是面积不大的各种楼前空地。小庭院按用途大致分为 住宅小庭院、小型公共庭院, 这两类庭院主要是在城市扩建过程中建造的, 基本没有确切的规划设计, 缺 乏公共绿地的建设与维护, 只有业主进行庭院绿化, 没有形成优良的生态环境, 因资金和面积所限, 很难 根据传统的造园法则设计建造, 所以打造精美的小型庭院要以植物造景为主, 按照使用者的需求合理规划 
小庭院的性质, 因地制宜的种植各类树木花草, 点缀以必要的园林小品, 形成具有中国特色的新型住宅区 域。成了景观设计师一项必要的任务。在现有江南小城市因地势而建设的低密度社区中，并没有空间的 “私 密感”, 园舍之间仅靠矮墙或栅栏隔开, 因此小庭院通过巧妙的植物围合布置, 可形成对内隐私或对外交 流的和谐空间。城市设计的重要人物 Jan Gehl 曾说过: “只有考虑人类尺度和互动的设计才是成功的设 计, ” 小庭院不同于绿地、公园，在使用上尤其特殊之处。此类庭院面积比较小，总体面积一般在 1 公顷 以内, 并具有较强的围合性。小庭院景观一般由植物、水体、铺装、小品等构成, 植物作为小庭院空间中 富有生命力和表现力的设计元素, 对于提升环境品质、丰富小庭院空间变化、提升视觉美感度具有独特的 作用，基于小庭院在环境、空间尺度、使用诉求等方面的独特性。

\section{2. 江南地区小庭院景观植物的空间营造}

在地理层面上来说，长江以南、南岭以北、武夷山和天目山以西、雪峰山以东，包括中国湘、赣两省 南部和浙西、皖南地区的大片低山和丘陵，总称江南丘陵。介于北纬 $25^{\circ} \sim 31^{\circ}$ ，东经 $110^{\circ} \sim 120^{\circ}$, 面积约 37 万平方公里。江南是个具有一致气候特点的地域, 这一地域的主要气候特点是: 江南的气候属于 亚热带季风性湿润气候, 温暖湿润、雨热同期, 河流广布, 植被茂密、土壤酸性较强 ${ }^{[1]}$ 。

植物在庭院设计的作用包括美化建筑外环境；实现提升环境适宜度、发挥生态效益的功能；营造、引 导空间和形成边界。通过乔、灌、藤本、地被的植物群落的种类的组合, 营造在视觉空间内高、中、低立 体的花境。在植物设计策略上要从满足业主的需求、服务于生活、耐用性强这三点出发。把握好庭院与环 境; 庭院与人之间的关系。

2.1 满足使用者需求 根据地理位置、地形、个人需求等原因小庭院植物设计是私人定制而不是流水线作 业。对植物设计的个性化需求要和业主进行沟通, 通过征询意见、场地分析等方式使这些需求在实际设计 中能够被满足。

2.2 服务于生活 包豪斯有句名言 “设计的目的是人，而不是产品。”太关注美观会导致设计只在图纸上是 漂亮的, 漂亮的设计有时缺少满足使用者需求的能力, 使用者的体验教导我们基于长远设计, 小庭院的植 物设计建造应该是以人为本的设计, 设计是沟通, 是传达, 是服务于大众。小庭院除了为供人们游赏、休 憩的休闲功能之外，还要与生活息息相关，供人们纳凉、晾晒、孩童玩要等。

2.3 耐用性强 例如学校小庭院、住宅小庭院这类面对特定人群使用频率高、反复使用。植物要易于养护, 不易被破坏。植物景观需要有持续的观赏性, 一年四季皆有景可赏。也就是说随着时间的退役, 植物景观 需要有明显的变化。这就在植物选择上匠心独具, 使得每个季节都有宜人的景致, 并随植物年龄的生长体 现出各植物的年龄美。

\section{3. 小型庭院景观设计要点}

\section{1 合理利用景观植物在小庭院中进行空间分层}

植物分类实现植物多样化注意植物配置的季相景观, 充分利用植物自身生长规律所产生的变化, 例如 花、果、叶、枝干随着四季在姿态、颜色、大小等的交替轮回。通过空间层次的划分为前景、中景、背景, 合理利用景观植物在小庭院中进行空间分层，在植物选择上，宜求精而忌繁杂，避免给人拥挤感。简约而 不简单, 精益求精是对此最好的诠释。在植物配植上, 设计者还应特别注意该地区特有的梅雨季节, 所以 应该优先选择本土植物, 本土植物对当地的气候条件、土壤条件和周边环境有很好的适应能力。下面介绍 
的植物大都符合此地区气候生长。从纵向上看, 植物主要占据三个层次, 乔木在最上面, 灌木从在中间, 地被植物在最底层，攀爬植物点缀立体空间。

(1). 基于小庭院面积等因素的考虑，尽量选择种植一些小乔木，树长成后树高能控制在 5-10 米，不 影响室内采光, 比如紫薇、沙漠玫瑰花期都在 5-9 月, 枝干优美、花色艳丽; 而近年果树（橘子树、无花 果树等）渐成庭院绿化“新宠”，逐渐在庭院绿化、美化中占据重要“席位”。

(2). 灌木的选择可分为常绿灌木和小型花灌木，常绿灌木比如瓜子黄杨或冬青等用来作为种植式隔 断, 是创造庭院整体性的良好方式, 在庭院边界或院内小径旁形成天然的功能分割起到围合空间、遮挡场 地的作用。

(3). 攀缘绿化, 利用藤本植物的生长特定, 可以布置成棚架绿化和垂直绿化。棚架绿化是一种常见的 分割空间的要素和装饰手法, 在各类庭院风格中占有重要地位, 可形成良好的户外休息空间。

(4). 地被植物, 在庭院中的布置面积比较大, 有类似于 “地毯” 的作用, 庭院中一些边缘角落和碎块 地也适合用地被植物来填充。地被植物品种可选择性大, 如麦冬、美女樱、五色梅、矮牵牛等草花类植物, 主要欣赏其本身特有的自然美以及植物组合的群体美, 配置在一起的各种花卉彼此间色彩、姿态、花期、 质地不一，对活跃庭院空间环境、点缀环境绿化起着十分重要的作用。

(5). 水生植物, 水体是庭院设计中不可或缺的元素, 水生植物也分为挺水植物浮水植物和沉水植物。 植物分布一般按照水深梯度的特有模式配置。在江南地区庭院力常用荷花、睡莲、浮萍这类挺水、浮水植 物来美化水体。

\section{2 色彩在小庭院植物配置设计中的运用}

颜色可以改变真实物体的三维视觉大小, 引导人们的视线, 增加园林景观深度。众所周知, 红色、黄 色、橙色等明度较高的色彩在视觉上是非常吸引人的, 它们有很强的主导作用, 能够吸引视线并缩短空间; 不同深浅的粉色、蓝色、紫色都是柔和色调, 这类宁静色彩在整体环境中可以增强其调和性, 形成低沉而 富有情感, 优雅柔和的植物景观。在色彩选择与搭配上要有主色、配色、基色之分。在小庭院中采用种植 式隔断, 以绿色作为背景, 像: 修剪整齐的绿篱、环绕式的自然种植, 使庭院更加具有整体性。冷色系如: 蓝雪花、琼花、玉䙃; 暖色系如: 大花金鸡菊、连翘、大花萱草等, 可伴随植物的质地感差异创造出绚丽 多彩的景观效果。设计小庭院里的植物配色方案, 要考量到每种植物的花期、赏叶最佳时期等自然因素, 按照季相、高低错落配置出层次才能制作出耐人寻味的景色。

\section{3 “道法自然” 的植物设计}

“与大自然和谐共处”、“环保”、“生态” 等理念被人们认识和接受, 设计师越来越多的将绿色植 物作为全新的设计手法运用到小庭院植物配置, 充分表达主人意愿和个性。植物的配置既要考虑配置的植 物在一段时间内生长之后产生的时空交换, 又要考虑由于这个变化所引起的空间、层次、形状、线条、色 彩等随之而来的变化。用植物营造个性化庭院空间, 小庭院, 尤其是住宅小庭院的风格可以是多种多样的, 这取决于家庭成员的喜好、实际需求以及家庭整体装修风格。刻意在自然庭院中是不应该出现的, 无匠气 的的营造景观环境, 将细节设计隐藏于无形, 考验的的是景观设计师的心思。只有做到 “道法自然” 才能 达到, “天人合一” 的效果。景观植物种类繁多, 选择不同的植物种植在私家庭院, 本身就是一种个性化 的表达。除了常见的观果类、观花类、观叶类等, 配置小型的观果类树种, 甚至可以有选择的种植一些蔬 
菜, 使得业主可以享受采摘的乐趣, 考虑到现代都市人群的休闲时间有限, 选择只需要适当的修剪和养护 的新型景观植物类型很有必要, 例如近几年大热的多肉植物、空气凤梨等, 只需付出低强度但能锻炼身心 的手工劳动。

\section{4. 结语}

小庭院空间的植物景观营造是一个有特色的研究领域, 植物作为景观构成要素之一在其他园林绿地空 间相比较的小庭院内作用更加凸显。但值得我们注意的是。然而尽管植物对小庭院来说极其重要, 但大部 分人仍然将植物作为装饰品或装扮建筑的陪祄物, 并且只看眼前, 在植物配置选择上脱离实际、不因地制 宜、徒劳费工, 浪费种苗和资金、景观效果也不明显。植物的选择原则要求应该确定在小庭院性质的基础 上, 以适地适树为前提, 优先选用本土植物, 适当搭配外来物种; 发挥植物的生长潜力, 预留出植物生长 空间; 使小庭院能随着岁月的流逝, 越发美丽。植物的空间营造是庭院设计的重要组成部分, 每人个人的 心中都有一座小庭院, 无论何种风格, 归根结底是一种生活, 一种态度, 由心做主。

\section{致谢}

基金项目：景德镇陶瓷大学校级青年项目（2013-06）

\section{Acknowledgment}

Fund Project: Jingdezhen Ceramic University Youth Project (2013-06)

\section{参考文献}

[1]黄东兵, 《园林规划设计》, 中国科学技术出版社 2003 年

[2]魏贻铮, 《庭院设计典例》, 中国林业出版社 2007 年

[3]周道瑛, 《园林种植设计》, 中国林业出版社 2008 年

[4]黄清俊, 《小庭院植物景观设计》, 化学工业出版社, 2011 年

\section{作者简介:}

张一帆 (1988--) 女, 江西景德镇人, 硕士, 景德镇陶瓷大学讲师, 主要研究方向: 景观设计/城市规划设计。

\section{References:}

[1] Huang Dongbing, "Landscape Planning and Design", China Science and Technology Press, 2003

[2] Wei Yizheng, "Courtyard Design", China Forestry Press, 2007

[3] Zhou Daoying, "Garden Planting Design", China Forestry Press, 2008

[4] Huang Qingjun, "Small courtyard plant landscape design", Chemical Industry Press, 2011 